\title{
New Prognostic Scoring System for Incurable Stage IV Colorectal Cancer
}

\author{
Tomokazu Kishiki*, Tadahiko Masaki, Hiroyoshi Mastuoka, Nobustugu Abe, \\ Toshiyuki Mori, Masanori Sugiyama
}

\begin{abstract}
Background: Components of the systemic inflammatory response, combined to form inflammation-based prognostic scores (mGPS, NLR, PLR, PI, PNI) have been associated with overall survival. The aim of the present study was to compare various prognostic factors including many previously established parameters and such systemic inflammation-based prognostic scores in a series of incurable stage IV colorectal cancer (CRC) patients. Materials and Methods: Patients $(n=167)$ with stage IV CRC undergoing surgical procedures between 2005 and 2013 were enrolled. Preoperatively (7-30 days before surgery), routine laboratory examinations were performed on the same day. We calculated scores using these data and analyzed the association with cancer specific survival (CSS) statistically. Results: Univariate analysis revealed significant associations between CSS and WBC, albumin, CRP, CEA values, mGPS, PNI, and PI values among preoperative factors. On multivariate analysis, high mGPS and high CEA independently predicted shorter CSS ( $p=0.001$ and $p=0.018)$. A new scoring system was constructed using mGPS and CEA. When patients were separated into three categorized using this system, the new score accurately predicted CSS $(p<0.001)$. Conclusions: The present study indicates that a new scoring system, consisting of mGPS and CEA, is a simple and useful tool in predicting the survival of patients with incurable stage IV CRC, and should be included in the routine assessment of these patients for decision making of appropriate treatment.
\end{abstract}

Keywords: Colorectal cancer - stage IV - GPS - CEA

Asian Pac J Cancer Prev, 17 (2), 597-601

\section{Introduction}

The survival of stage IV colorectal cancer (CRC) patients has improved because of advances in both surgery and chemotherapy. Nevertheless, only $<15 \%$ of these patients survive for more than 5 years (Rosen, et al., 2000). The patient-dependent parameters, such as age, medical comorbidities, extent of distant metastases, and local invasion are the well-established factors that may influence the decision making on whether a curative or palliative operation, or a non-operative treatment should be selected in such cases. However, postoperative survival cannot be accurately predicted. Therefore, there are lots of ongoing studies to identify more accurate prognostic factors that will allow appropriate patient stratification.

Prognosis is determined by several factors, of which the specific tumor stage and biology- and patient-related factors are particularly important, and the prognosis can potentially be modified by treatment. There is a wide range of patient- or tumor-related, and biochemical prognostic factors (Schmoll, et al., 2012). A previous study identified 10 factors that were associated with a poor prognosis in advanced CRC: performance status $\geq 2$, age $\geq 70$ years, carcinoembryonic antigen (CEA) $>50 \mu \mathrm{g} / \mathrm{l}$, alkaline phosphatase $(\mathrm{ALP}) \geq 300 \mathrm{U} / 1$, platelet count $(\mathrm{PLT}) \geq 400$ $\times 10^{9} / 1$, hemoglobin $(\mathrm{Hb})<11 \mathrm{~g} / \mathrm{dl}$, white blood cell count $(\mathrm{WBC}) \geq 10 \times 10^{9} / 1$, high lactate dehydrogenase (LDH) levels, low serum albumin levels, and the presence of the BRAF mutation (Schmoll, et al., 2012).

With regard to the measures of systemic inflammatory response, the combination of C-reactive protein (CRP) and albumin-i.e., the original Glasgow prognostic score (original GPS) and modified GPS (mGPS)-has been shown to improve the accuracy with which cancerspecific survival can be predicted in various common solid malignancies (McMillan, et al., 2007). Furthermore, we have previously reported a relationship between mGPS and prognosis in incurable stage IV CRC patients undergoing surgery (Kishiki, et al., 2013). The mGPS score (0 and 1 , low; 2 , high) $(\mathrm{P}=0.0001)$ were significant predictive factors for postoperative mortality. The mGPS is simple and useful as a novel predictor of postoperative survival in patients with incurable stage IV colorectal cancer (Kishiki, et al., 2013).

Moreover, other hematological components of the systemic inflammatory response have been combined 
to create an inflammation-based prognostic score that is associated with survival in cancer patients (Table 1). The neutrophil lymphocyte ratio (NLR), a combination of circulating neutrophil and lymphocyte counts (Walsh, et al., 2005), has been associated with survival in lung (Sarraf, et al., 2009; Kao, et al., 2010), and ovarian (Cho, et al., 2009) cancer, whereas the platelet and lymphocyte ratio (PLR), a combination of circulating platelet and lymphocyte counts, has been indicated to predict survival in pancreatic cancer (Smith, et al., 2009). The CRP and WBC values have been combined to form a prognostic index (PI) that has been shown to be associated with lung cancer (Kasymjanova, et al., 2010). Finally, Onodera's prognostic nutritional index (PNI) has also been found to be associated with survival in patients with pancreatic (Kanda, et al., 2011), gastric (Nozoe, et al., 2010), and esophageal cancer (Nozoe, et al., 2002).

However, to our knowledge, there have been no reports on the comparison of various prognostic factors including many previously established prognostic factors (Schmoll, et al., 2012) and the systemic inflammationbased prognostic scores described above in incurable stage IV CRC patients. The aims of this study were to examine the relationship between preoperative prognostic factors, including inflammation based prognostic factors, and cancer specific survival (CSS) in patients with incurable stage IV CRC, to compare these prognostic factors, and to propose a new prognostic factor.

\section{Materials and Methods}

Between January 2005 and December 2013, 167 patients with incurable stage IV CRC were treated with resection only of a primary lesion $(n=128)$, bypass surgery $(n=3)$, colostomy $(n=19)$ or chemotherapy alone $(n=17)$ in our department. Preoperatively (7-30 days before surgery), routine laboratory examinations, including those for the levels of $\mathrm{Hb}, \mathrm{WBC}, \mathrm{PLT}, \mathrm{CRP}$, albumin, ALP,

Table 1. Systemic Inflammation-based Prognostic Scores

\begin{tabular}{lr}
\hline Modified Glasgow Prognostic Score $(\mathrm{mGPS})$ & Score \\
\hline C-reactive protein $\leq 10 \mathrm{mg} / \mathrm{l}$ and albumin $\geq 35 \mathrm{~g} / 1$ & 0 \\
C-reactive protein $\leq 10 \mathrm{mg} / \mathrm{l}$ and albumin $<35 \mathrm{~g} / 1$ & 0 \\
C-reactive protein $>10 \mathrm{mg} / 1$ & 1 \\
C-reactive protein $>10 \mathrm{mg} / 1$ and albumin $<35 \mathrm{~g} / 1$ & 2 \\
Neutrophil Lymphocyte Ratio (NLR) & 0 \\
Neutrophil count: lymphocyte count $<5: 1$ & 1 \\
Neutrophil count: lymphocyte count $\geq 5: 1$ & 0 \\
Platelet Lymphocyte Ratio (PLR) & 1 \\
Platelet count: lymphocyte count $<150: 1$ & 2 \\
Platelet count: lymphocyte count $150-300: 1$ & \\
Platelet count: lymphocyte count $>300: 1$ & \\
Prognostic Index $(\mathrm{PI})$ & \\
C-reactive protein $\leq 10 \mathrm{mg} / 1$ and white cell count $\leq 10 \times 10^{9} / 10$ \\
C-reactive protein $\leq 10 \mathrm{mg} / 1$ and white cell count $>10 \times 10^{9} / 11$ \\
C-reactive protein $>10 \mathrm{mg} / 1$ and white cell count $\leq 10 \times 10^{9} / 11$ \\
C-reactive protein $>10 \mathrm{mg} / 1$ and white cell count $>10 \times 10^{9} / 12$ \\
Prognostic Nutritional Index (PNI) \\
Albumin $(\mathrm{g} / \mathrm{L})+5 \times$ total lymphocyte count $\times 10^{9} / 1 \geq 45$ \\
Albumin $(\mathrm{g} / \mathrm{L})+5 \times$ total lymphocyte count $\times 10^{9} / 1<45$ \\
\hline
\end{tabular}

LDH, and tumor markers such as CEA and carbohydrate antigen 19-9 (CA19-9), were performed on the same day. Inflammation based prognostic scores(mGPS, NLR, PLR, PI and PNI)were calculated (Table1). This study was approved by the Research Ethics Committee, Hospital of Kyorin University School of Medicine.

\section{Statistical Analysis}

Values are presented as the mean and range $(95 \%$ confidence interval). Cases who died before the end of December 2013 were included in the analysis.

CSS was calculated from the start of treatment to the last follow-up or death, using the Kaplan-Meier method. Comparisons between different groups were performed using log-rank tests. To identify the independent factors, multivariate analyses were performed using a logistic regression model for response and a Cox regression model

\section{Table 2. Patient Demographic Characteristics}

\begin{tabular}{|c|c|c|}
\hline Variables & $\mathrm{N}$ & $\%$ \\
\hline Overall & 167 & \\
\hline Age $($ years $)(<70 / \geq 70)$ & $97 / 70$ & $58 / 42$ \\
\hline Sex (Male / Female) & $102 / 65$ & $61 / 39$ \\
\hline Site of tumor (Colon / Rectum) & $100 / 67$ & $60 / 40$ \\
\hline Haemoglobin $(<11 \mathrm{~g} / \mathrm{dl} / \geq 11 \mathrm{~g} / \mathrm{dl})$ & $114 / 53$ & $68 / 32$ \\
\hline $\operatorname{WBC}\left(<10 \times 10^{9} / 1 / \geq 10 \times 10^{9} / 1\right)$ & $131 / 36$ & $78 / 22$ \\
\hline Platelets $\left(<400 \times 10^{9} / 1 / \geq 400 \times 10^{9} / 1\right)$ & $134 / 32$ & $81 / 19$ \\
\hline $\operatorname{ALP}(<300 \mathrm{U} / 1 / \geq 300 \mathrm{U} / 1)$ & $76 / 84$ & $48 / 52$ \\
\hline $\mathrm{LDH}(<220 \mathrm{U} / 1 / \geq 220 \mathrm{U} / 1)$ & $60 / 71$ & $46 / 54$ \\
\hline $\operatorname{Albumin}(\geq 3.5 \mathrm{~g} / \mathrm{dl} /<3.5 \mathrm{~g} / \mathrm{dl})$ & $104 / 63$ & $62 / 38$ \\
\hline $\mathrm{CRP}(<10 \mathrm{mg} / \mathrm{dl} / \geq 10 \mathrm{mg} / \mathrm{dl})$ & $81 / 86$ & $49 / 51$ \\
\hline $\mathrm{CEA}(\leq 50 \mu \mathrm{g} / 1 />50 \mu \mathrm{g} / \mathrm{l})$ & $94 / 69$ & $58 / 42$ \\
\hline CA19-9 $(<37 / \geq 37)$ & $77 / 85$ & $48 / 52$ \\
\hline mGPS $(0 / 1 / 2)$ & $\begin{array}{l}78 / 43 \\
/ 46\end{array}$ & $\begin{array}{c}55 / 22 \\
/ 23\end{array}$ \\
\hline $\operatorname{NLR}(<5 / \geq 5)$ & $100 / 55$ & $65 / 35$ \\
\hline $\operatorname{PLR}(<150 / 150-300 />300)$ & $\begin{array}{c}45 / 74 \\
133\end{array}$ & $\begin{array}{c}30 / 47 \\
/ 23\end{array}$ \\
\hline $\mathrm{PI}(0 / 1 / 2)$ & $\begin{array}{c}73 / 78 \\
/ 16\end{array}$ & $\begin{array}{c}40 / 47 \\
/ 13\end{array}$ \\
\hline PNI $(0 / 1)$ & $74 / 83$ & $47 / 53$ \\
\hline Site of tumor (Colon / Rectum) & $100 / 67$ & $60 / 40$ \\
\hline $\begin{array}{l}\text { Maximum diameter of tumor }(\mathrm{mm}) \\
(<50>50)\end{array}$ & $59 / 77$ & $43 / 57$ \\
\hline $\begin{array}{l}\text { Differentiation of tumor (tub1, tub2 / } \\
\text { Others) }\end{array}$ & $146 / 15$ & $91 / 9$ \\
\hline Depth of wall invasion (T2-T3 / T4) & $61 / 73$ & $46 / 54$ \\
\hline Liver metastasis $(-/+)$ & $46 / 121$ & $28 / 72$ \\
\hline Lung metastasis $(-/+)$ & $112 / 55$ & $67 / 33$ \\
\hline Peritoneal dissemination $(-/+)$ & $108 / 59$ & $65 / 35$ \\
\hline Distant metastasis $(-/+)$ & $144 / 23$ & $86 / 14$ \\
\hline Numbers of metastasis $(1 / \geq 2)$ & $106 / 61$ & $63 / 37$ \\
\hline Tumor Resection $(-/+)$ & $39 / 128$ & $33 / 77$ \\
\hline Adjuvant chemotherapy (-/+) & $56 / 110$ & $34 / 66$ \\
\hline
\end{tabular}

ALP,alkaline phosphatase; LDH,high lactate dehydrogenase; CRP, C-reactive protein; CEA,carcinoembryonic antigen; CA199,carbohydrate antigen 19-9; mGPS, modified Glasgow prognostic score; NLR,neutrophil lymphocyte ratio; PLR, platelet and lymphocyte ratio; $\mathrm{PI}$, prognostic index; PNI, prognostic nutritional index 
Table 3. Univariated Analysis of Preoperative Factors

\begin{tabular}{|c|c|c|c|c|c|c|}
\hline \multirow[b]{2}{*}{ Variables } & \multicolumn{3}{|c|}{ Univariate } & \multicolumn{3}{|c|}{ Multivariate } \\
\hline & HR & $(95 \% \mathrm{CI})$ & P-value & HR & $(95 \% \mathrm{CI})$ & P-value \\
\hline Age $($ years $)(<70 />70)$ & 0.64 & $0.4-1.1$ & 0.080 & & & 0.140 \\
\hline Sex (Male / Female) & 1.31 & $0.80-2.12$ & 0.282 & & & \\
\hline Site of tumor (Colon / Rectum) & 1.18 & $0.72-1.90$ & 0.511 & & & \\
\hline Haemoglobin $(<11 \mathrm{~g} / \mathrm{dl} />11 \mathrm{~g} / \mathrm{dl})$ & 1.60 & $0.96-2.65$ & 0.070 & & & 0.993 \\
\hline WBC $(<10 \times 109 / 1 / \geq 10 \times 109 / 1)$ & 1.89 & $1.11-3.21$ & 0.018 & & & 0.085 \\
\hline Platelets $(<400 \times 109 / 1 / \geq 400 \times 109 / 1)$ & 1.19 & $0.69-2.05$ & 0.536 & & & \\
\hline $\operatorname{ALP}(<300 \mathrm{U} / 1 / \geq 300 \mathrm{U} / 1)$ & 1.64 & $1.01-2.66$ & 0.044 & & & 0.467 \\
\hline $\mathrm{LDH}(<220 \mathrm{U} / \mathrm{l} / \geq 220 \mathrm{U} / \mathrm{l})$ & 1.60 & $0.99-2.61$ & 0.057 & & & 0.274 \\
\hline Albumin $(\geq 3.5 \mathrm{~g} / \mathrm{dl} /<3.5 \mathrm{~g} / \mathrm{dl})$ & 2.43 & $1.53-3.86$ & $<0.0001$ & & & 0.361 \\
\hline $\mathrm{CRP}(<10 \mathrm{mg} / \mathrm{dl} / \geq 10 \mathrm{mg} / \mathrm{dl})$ & 2.70 & $1.67-4.38$ & $<0.0001$ & & & 0.118 \\
\hline $\mathrm{CEA}(\leq 50 \mu \mathrm{g} / \mathrm{l} />50 \mu \mathrm{g} / \mathrm{l})$ & 2.40 & $1.46-3.95$ & 0.001 & 2 & $(1.1-3.4)$ & 0.018 \\
\hline CA19-9 $(<37 / \geq 37)$ & 1.25 & $0.77-2.02$ & 0.365 & & & \\
\hline mGPS $(0 / 1$ / 2) & 1.98 & $1.52-2.59$ & $<0.0001$ & 1.8 & $(1.3-2.5)$ & $<0.0001$ \\
\hline $\operatorname{NLR}(<5 / \geq 5)$ & 1.47 & $0.89-2.41$ & 0.131 & & & \\
\hline $\operatorname{PLR}(<150 / 150-300 />300)$ & 1.00 & $1.00-1.00$ & 0.096 & & & 0.744 \\
\hline $\mathrm{PI}(0 / 1 / 2)$ & 2.11 & $1.51-2.96$ & $<0.0001$ & & & 0.453 \\
\hline PNI $(0 / 1)$ & 1.81 & $1.11-2.94$ & 0.017 & & & 0.990 \\
\hline
\end{tabular}

HR, hazard ratio; CI, confidence interval; ALP, alkaline phosphatase; LDH, high lactate dehydrogenase; CRP, C-reactive protein; CEA, carcinoembryonic antigen; CA19-9,carbohydrate antigen 19-9; mGPS, modified Glasgow prognostic score; NLR, neutrophil lymphocyte ratio; PLR, platelet and lymphocyte ratio; PI, prognostic index; PNI, prognostic nutritional index

Table 4. New Scoring System

\begin{tabular}{|c|c|c|c|c|c|c|}
\hline \multirow{2}{*}{ Variables } & \multirow[t]{2}{*}{$\mathrm{N}$} & \multicolumn{2}{|c|}{ CSS (months) } & \multirow[t]{2}{*}{ HR } & \multirow[t]{2}{*}{$(95 \% \mathrm{CI})$} & \multirow[t]{2}{*}{ P-value } \\
\hline & & Median & $95 \% \mathrm{CI}$ & & & \\
\hline mGPS 0 and $\mathrm{CEA} \leq 50$ & 53 & 69.8 & $38.6-59.1$ & 1.0 & & \\
\hline mGPS 0 and CEA $>50$, mGPS 1 and CEA $\leq 50$ or $>50$ & 83 & 23.3 & $17.2-9.6$ & 3.0 & $2.0-7.7$ & \\
\hline mGPS 2 and $C E A>50$ & 20 & 8.3 & $7.0-9.6$ & 9.1 & 4.1-19.9 & 0.000 \\
\hline
\end{tabular}

HR, hazard ratio; CI, confidence interval; mGPS, modified Glasgow prognostic score; CEA, carcinoembryonic antigen

for CSS. Two-tailed $\mathrm{p}$ values of $<0.05$ were considered significant. All analyses were performed using computer software IBM ${ }^{\circledR}$ SPSS ${ }^{\circledR}$ (Statistical Package for Social Sciences) Statistics version 20.0 for Mac.

\section{Results}

\section{Patient characteristics}

The median follow-up period of this study was 23.5 months (range, 1-85 months). Baseline patients characteristic are shown in Table 2 . The study included 102 men and 65 women, and 100 patients had colon cancer and 67 had rectal cancer. The postoperative mortality rate was $1.2 \%(2 / 167)$. The postoperative complication rate was $7.8 \%(13 / 167)$.

Univariate analysis revealed significant association between CSS and WBC, ALP, albumin, CRP, CEA values, mGPS, PNI, and PI values among preoperative factors. (Table 3) In multivariate analysis on all factors, high mGPS and high CEA $(\geq 50 \times \mu \mathrm{g} / \mathrm{l})$ independently predicted shorter CSS, respectively. (Table 3 )

\section{New Score: Inflammation-based score using mGPS and} $C E A$

Based on the results of the multivariate analysis, a

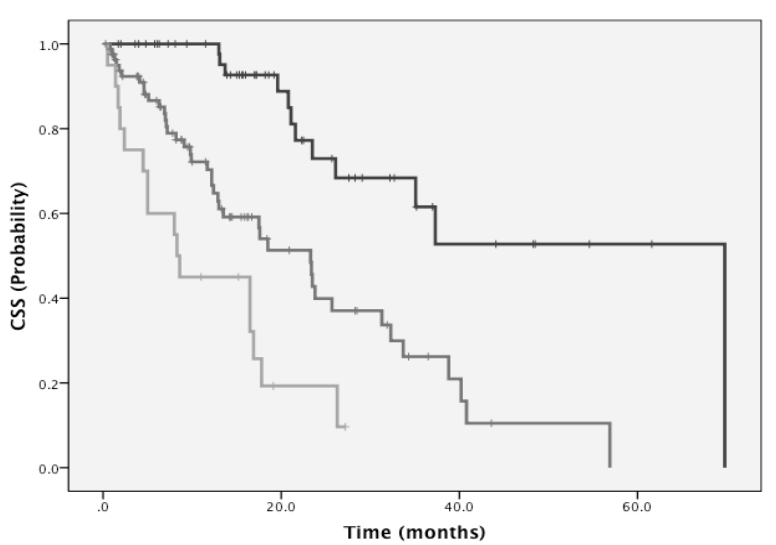

Figure 1. CSS Curves After Surgery. The black line represents new score A; the most light gray line represents new score B; and the gray line represents new score C. Three-year survival rates of patients with a predicted score of $\mathrm{A}, \mathrm{B}$, and $\mathrm{C}$ were $61.5 \%, 26.2 \%$, and $0 \%$, respectively. One-year survival rates of patients with a predicted score of $\mathrm{A}, \mathrm{B}$, and $\mathrm{C}$ were $97.6 \%, 70 / 3 \%$, and $45.0 \%$, respectively. This simple scoring system was found to be highly predictive of the long-term outcome $(\mathrm{P}<0.0001)$

new score using mGPS and CEA were constructed. Using this combined score, patients were categorized into three 
categories. This scoring system accurately predicted CSS; median CSS was 69.8 months in category A, 23.3 months in category $\mathrm{B}$, and 8.3 months in category $\mathrm{C}(\mathrm{p}<0.0001)$. (Table 4) (Figure 1)

\section{Discussion}

Inflammatory processes almost always accompany cancer progression. Inflammation in the tumor microenviroment plays an important role in tumorigenesis, tumor promotion, tumor invasion, and metastasis through the recruitment of regulatory $\mathrm{T}$ lymphocytes and chemokines, activation of cytokines interleukin- 6 and tumor necrosis factor-alpha, induction of neutrophilia, and secretion of CRP.

However, most studies have focused on one of these predictive factors. Only a few studies have compared and evaluated many factors, except for a recent large cohort study (Glasgow Inflammation Outcome Study) comparing the prognostic value of the mGPS, NLR, PLR, PI, and PNI at different tumor sites (Proctor, et al., 2011).

Our findings of a positive association between an elevated mGPS and poorer prognosis are consistent with other studies (Crumley, et al., 2006).

This implied role of inflammation in cancer progression is supported by ongoing research on the effect of aspirin and other non-steroidal anti-inflammatory drugs on prevention of tumors, including cancers of the colon, lung, esophagus, stomach and bladder (Baron, et al., 2000; Langman, et al., 2000; Garcia-Rodriguez, et al., 2001; Daugherty, et al., 2011). Based on our results, we suggested that the modification of the preoperative systemic inflammatory response in patients with stage IV CRC could also be a worthwhile research focus.

CEA can use in assessing the prognosis of the patients with metastatic CRC. CEA levels $(>50 \mu \mathrm{g} / \mathrm{l})$ was established poor prognostic factors in advanced CRC (Schmoll, et al., 2012). The results of this study support the usefulness of new scores (mGPS and CEA) for predicting CSS in patients with incurable stage IV CRC. Previous report showed that mGPS and CEA accurately predict OS in patients with liver metastasis from CRC (Kobayashi, et al., 2014).

Furthermore, a combination score using both these indices was able to categories patients into three categories with significant differences in CSS. Between patients with normal status as defined by mGPS score 0 and CEA levels $\left(\leq 50 \times 10^{9} / 1\right)$ (median OS: 69.8 months) and patients with high score (median CSS: 8.3 months), a clinically significant difference of 61 months was noted. (Figure 1)

This study confirms not only the utility of GPS (McMillan, et al., 2007; Kishiki, et al., 2013), but also the utility of CEA in predicting clinical outcomes in patients with incurable stage IV CRC.

Taken together, the results of the present study highlighted the importance of systemic inflammation in the poor outcome in patients with stage IV CRC. If this proves to be the case, then modulation of the systemic inflammatory response will become, in the future, an important therapeutic target in patients with incurable stage IV CRC. The limitations of the present study include its retrospective, single-center design and a potential bias in the selection of patients. It is well known that the tumor factors and postoperative factors are good prognostic indicators in patients with CRC, however, we could show that the analysis of pretreatment data was useful for decision making of appropriate treatment.

The present study indicates that a new scoring system, consisting of mGPS and CEA, is a simple and useful tool in predicting the survival of patients with incurable stage IV CRC, and should be included in the routine assessment of these patients for decision making of appropriate treatment.

\section{References}

Baron JA, Sandler RS (2000). Nonsteroidal anti-inflammatory drugs and cancer prevention. Annu Rev Med, 51, 511-23.

Cho H, Hur HW, Kim SW, et al (2009). Pre-treatment neutrophil to lymphocyte ratio is elevated in epithelial ovarian cancer and predicts survival after treatment. Cancer Immunol Immunother, 58, 15-23.

Crumley AB, McMillan DC, Mckernan M, et al (2006). An elevated c-reactive protein concentration, prior to surgery, predicts poor cancer-specific survival in patients undergoing resection for gastro-oesophageal cancer. Br J Cancer, 94, 1568-71.

Crumley AB, McMillanDC, McKernan M, et al (2006). Evaluation of an inflammation-based prognostic score in patients with inoperable gastoro-oesophageal cancer. $\mathrm{Br} J$ Cancer, 94, 637-41.

Daugherty SE, Pfeiffer RM, Sigurdson AJ, et al (2011). Nonsteroidal antiinflammatory drugs and bladder cancer: a pooled analysis. Am J Epidemiol, 173, 721-30.

García-Rodríguez LA, Huerta-Alvarez C (2001). Reduced risk of colorectal cancer among long-term users of aspirin and nonaspirin nonsteroidal antiinflammatory drugs. Epidemiol, 12, 88-93.

Kanda M, Fujii T, Kodera Y, et al (2011). Nutritional predictors of postoperative outcome in pancreatic cancer. Br J Surg, 98, 268-74.

Kao SC, Pavlakis N, Harvie R, et al (2010). High blood neutrophil-to-lymphocyte ratio is an indicator of poor prognosis in malignant mesothelioma patients undergoing systemic therapy. Clin Cancer Res, 16, 5805-13.

Kasymjanova G, MacDonald N, Agulnik JS, et al (2010). The predictive value of pre-treatment inflammatory markers in advanced non-small-cell lung cancer. Curr Oncol, 17, 52-8.

Kishiki T, Masaki T, Matsuoka H, et al (2013). Modified glasgow prognostic score in patients with incurable stage IV colorectal cancer. Am J Surg, 206, 234-40.

Kobayashi T, Kawakami M, Kara Y, et al (2014). Combined evaluation of the Glasgow prognostic score and carcinoembryonic antigen concentration prior to hepatectomy predicts postoperative outcomes in patients with liver metastasis from colorectal cancer. Hepatogastroenterol, 133, 1359-62

Langman MJ, Cheng KK, Gilman EA, et al (2000). Effect of anti-inflammatory drugs on overall risk of common cancer: case-control study in general practice research database. $B M J$, 320, 1642-6.

McMillan DC, Crozier JE, Canna K, et al (2007). Evaluation of an inflammation-based prognostic score (GPS) in patients undergoing resection for colon and rectal cancer. Int $J$ Colorectal Dis, 22, 881-6.

Nozoe T, Kimura Y, Ishida M, et al (2002). Correlation of pre-operative nutritional condition with post-operative 
complications in surgical treatment for oesophageal carcinoma. Eur J Surg Oncol, 28, 396-400.

Nozoe T, Ninomiya M, Maeda T, et al (2010). Prognostic nutritional index: A tool to predict the biological aggressiveness of gastric carcinoma. Surg Today, 40, 440-3.

Proctor MJ, Morrison DS, Talwar D, et al (2011). A comparison of inflammation-based prognostic scores in patients with cancer. A glasgow inflammation outcome study. Eur $J$ Cancer, 47, 2633-41.

Rosen SA, Buell JF, Yoshida A, et al (2000). Initial presentation with stage IV colorectal cancer: How aggressive should we be? Arch Surg, 4, 534-5.

Sarraf KM, Belcher E, Raevsky E, et al (2009). Neutrophil/ lymphocyte ratio and its association with survival after complete resection in non-small cell lung cancer. $J$ Thorac Cardiovasc Surg, 137, 425-8.

Schmoll HJ, Van Cutsem E, Stein A, et al (2012). ESMO consensus guidelines for management of patients with colon and rectal cancer. a personalized approach to clinical decision making. Ann Oncol, 23, 2479-516.

Smith RA, Bosonnet L, Raraty M, et al (2009). Preoperative platelet-lymphocyte ratio is an independent significant prognostic marker in resected pancreatic ductal adenocarcinoma. Am J Surg, 197, 466-72.

Walsh SR, Cook EJ, Goulder F, et al (2005). Neutrophillymphocyte ratio as a prognostic factor in colorectal cancer. J Surg Oncol, 91, 181-4. 